\title{
Funneled flow mechanisms in a sloping layered soil: Laboratory investigation
}

\author{
M. T. Walter, ${ }^{1}$ J.-S. Kim, ${ }^{2}$ T. S. Steenhuis, ${ }^{3}$ J.-Y. Parlange, ${ }^{3}$ A. Heilig, ${ }^{3}$ \\ R. D. Braddock, ${ }^{4}$ J. S. Selker, ${ }^{5}$ and J. Boll ${ }^{6}$
}

\begin{abstract}
Artificial capillary barriers are being used to divert water away from sensitive underground regions. Conversely, funneled flow over natural capillary barriers may increase the danger of groundwater contamination by decreasing the travel time and contact area. There have been relatively few experimental studies of capillary barrier flow patterns. In this study, water was applied uniformly across the top surface of a backlit tilting chamber, $1 \mathrm{~cm}$ thick, $110 \mathrm{~cm}$ high, and $180 \mathrm{~cm}$ long, in which a coarse sand layer was imbedded in a fine sand. Bedding slope and water application rates were varied between $0^{\circ}$ and $12^{\circ}$ and 1 and $3 \mathrm{~cm} \mathrm{~h}^{-1}$, respectively. After attaining steady state, matric potential was measured along the textural interface, and photos of dye traces were taken in order to visualize streamlines. The funneled flow was characterized by three discrete regions: an initial capillary diversion, a breakthrough region, and a toe diversion. The breakthrough region consisted of a significant zone of partial breakthrough where the vertical flux into the coarse layer was less than the water application rate. The lateral distance of the capillary diversion was explained well by previously published relationships when the water entry value at the textural interface was replaced by lower, observed matric potential at which breakthrough occurred at the most upslope point. The length of the capillary diversion was overpredicted using the air entry value. Finally, the toe of the coarse layer had significant, observed effects on funneled flow patterns, which have previously received little, if any, attention. The results of this study imply that the slope of the coarse layer and infiltration rate will largely govern the effectiveness of capillary barriers and that capillary barriers are less effective than previously assumed.
\end{abstract}

\section{Introduction}

Preferential flow has been implicated in the increased rate of contaminant transport, particularly pesticides, to groundwater [Steenhuis and Parlange, 1991; Flury, 1996]. Preferential flow is defined as the uneven movement of water and solutes through porous media, typically soil, characterized by regions of enhanced flux such that a small fraction of the media participates in most of the flow. There are a number of preferential flow mechanisms: (1) physical conduits such as macropores, structural cracks, and biopores that provide preferential paths through which water may be rapidly transmitted [Bouma, 1981; Beven, 1981; Beven and Germann, 1982]; (2) finger phenomena, in either layered [Hill and Parlange, 1972] or nonlayered soils [Tamai et al., 1987; Selker et al., 1992], that arises from wetting-front instability [Parlange and Hill, 1976; Hillel, 1987;

\footnotetext{
${ }^{1}$ Department of Environmental Science, University of Alaska, Juneau.

${ }^{2}$ Department of Agricultural Engineering, Chungbuk National University, Chongju, South Korea.

${ }^{3}$ Department of Agricultural and Biological Engineering, Cornell University, Ithaca, New York.

${ }^{4}$ Environmental Sciences, Griffith University, Nathan, Queensland, Australia.

${ }^{5}$ Department of Bioresource Engineering, Oregon State University, Corvallis.

${ }^{6}$ Department of Biological and Agricultural Engineering, University of Idaho, Moscow.

Copyright 2000 by the American Geophysical Union.

Paper number 1999WR900328.

0043-1397/00/1999WR900328\$09.00
}

Glass et al., 1989]; and (3) lateral flow, in which the flow of water and solutes is concentrated and moves laterally along an inclined soil-layer interface. Theoretical understanding and subsequent mathematical descriptions of the pertinent hydraulic mechanisms are critical to anticipating and preventing groundwater pollution. This study investigates preferential flow due to lateral flow.

There are two primary mechanical categories of lateral flow. The most familiar category is typically referred to as saturated interflow [Betson et al., 1968], subsurface storm flow [Hursh, 1936], or throughflow [Kirby and Chorley, 1967] and may occur where an upper soil region is underlain by a hydraulically restrictive layer such as bedrock or a fragipan [Hewlett and Hibbert, 1963; Whipkey, 1965; Dunne and Black, 1970; Pilgram et al., 1978; Stagnitti et al., 1986]. Because of the low permeability of the underlying layer, water moving vertically through a soil profile is partially impeded at the interface causing water to accumulate above the restrictive layer and to flow laterally across it (downslope). The second major category, first shown by Gardner [1960], is commonly now referred to as funneled flow [Kung, 1990]. Funneled flow is an unique category of flow phenomena referring to the situation in which a capillary barrier develops above a coarse layer which underlies a relatively fine soil [Miyazaki, 1988; Kung, 1990; Steenhuis et al., 1990]. At low flows, when the matric potential at the textural interface is so low that water cannot enter into the coarse, underlying soil, the capillary barrier effectively restricts vertical water flux, forcing the water to move laterally along the bedding interface. Capillary barriers have received increased attention as an application for isolating buried wastes from hydrologic fluxes 


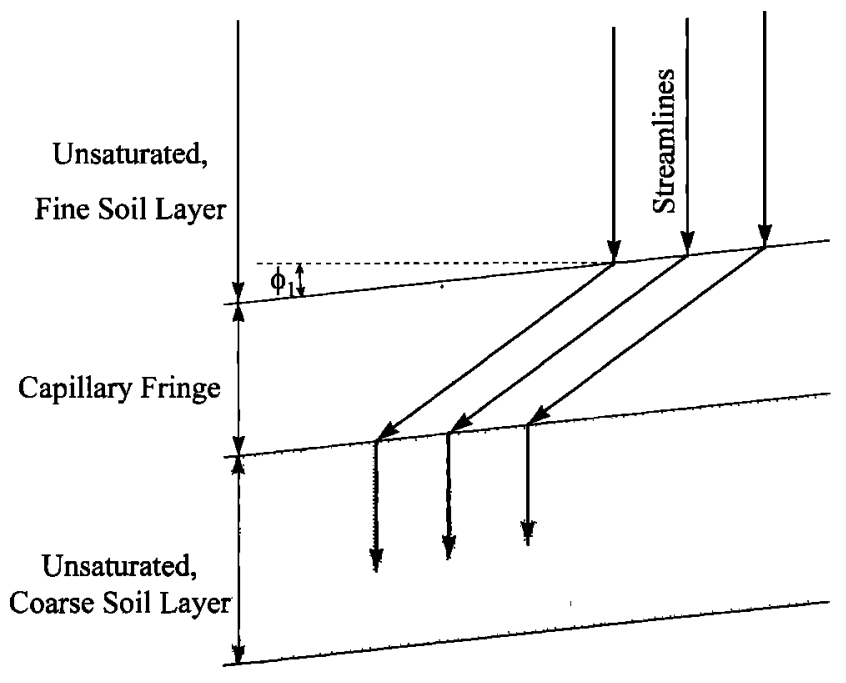

Figure 1. Schematic of the funneled flow system divided vertically into three regions and a graphical representation of deflection of streamlines as they pass the boundaries between regions. Here $\phi_{1}$ is the slope of the coarse layer.

[Morris and Stormont, 1997; Selker, 1997]. Zaslavsky and Sinai [1981], Mualem [1984], and Yeh et al. [1985] studied lateral flow caused by several layers of fine and coarse soil.

We will focus in this study on the flow over and through capillary barriers. Three regions are distinguished (Figure 1): an upper unsaturated, fine soil layer region; a lower unsaturated, coarse soil region; and, between these two, a tensionsaturated fine layer or capillary fringe. The capillary fringe is wettest near the coarse-fine interface and is drier near the upper edge of the fringe. Because of textural differences between the layers, there can be a sharp boundary between soil moisture contents; that is, though the matric potential is continuous across the soil layer interface, differences in pore size distributions between the layers result in discrete differences in moisture content.

It is commonly assumed that the "water entry" suction value [Hillel and Gardner, 1970; Hillel and Baker, 1988] of the underlying coarse layer is a critical parameter for describing and/or predicting flow through textural interfaces. The water entry value, generally considered a property of the underlying soil, was measured by both Hillel and Gardner [1970] and Hillel and Baker [1988] for horizontal layering as the potential at the interface after the water started to flow across the interface. It will be referred to as the effective interface water entry matric potential.

At the textural interface both the quantity of flow and matric potential increase downslope. Once the potential increases to a high enough value, water will start moving downward into the

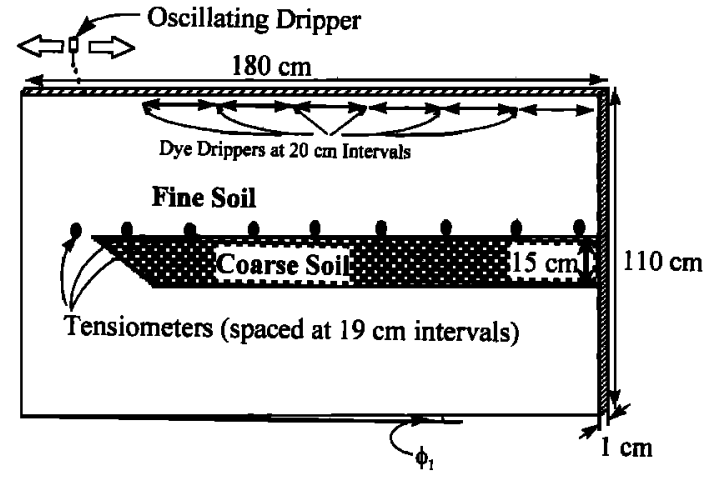

Figure 2. Schematic of the experimental setup (not to scale).

coarse layer. The vertical movement of water into the coarse layer is referred to as breakthrough. Ross [1990] calculated for steady state conditions the distance to where there is no net downslope lateral flow beyond the point of breakthrough; $P$ an et al. [1997] simulated transient flow through sloping layers and found that the flow of water is directed partially upslope during heavy rains. Modeling studies by Oldenberg and Pruess [1993] and Webb [1997] suggested a partial breakthrough region along the fine-coarse interface in which, at steady state, the vertical flux is less than the water application rate. There is disagreement in these modeling studies about how the flow changes in the partial breakthrough region.

There have been few detailed laboratory studies where the flow through and along the interface have been measured. The objective of this paper is to give better information on the flow through and along the capillary barriers under well-controlled conditions. Specifically, this study (1) qualitatively characterizes the funnel flow regimes along a fine over coarse layer interface of finite length under constant rainfall intensity; (2) describes, explains, and quantifies the effects of the rainfall rate and slope on these regimes; and (3) defines measured parameters for quantifying funnel flow and breakthrough.

\section{Materials and Methods}

Figure 2 is a schematic of the experimental setup. Experiments were performed in a glass chamber $180 \mathrm{~cm}$ long, $110 \mathrm{~cm}$ high, and $1 \mathrm{~cm}$ thick, backlit with high-intensity fluorescent light to help visualize the streamlines and the distribution of moisture content [Glass et al., 1989]. The chamber was filled with fine sand embedded with a $15 \mathrm{~cm}$ thick, $160 \mathrm{~cm}$ long layer of coarse sand. Relevant properties of the fine and coarse sand are shown in Table 1. Figure 3 shows the characteristic matric potential versus soil moisture relationships for the two sands. Spatially uniform rainfall was applied over the top of the chamber using a single, chain-driven, oscillating dropper. The slope

Table 1. Physical Properties of the Soils Used in the Study

\begin{tabular}{|c|c|c|c|c|c|c|c|}
\hline \multirow[b]{2}{*}{ Type } & \multicolumn{5}{|c|}{ Weight of Particle Size Classes, ${ }^{*} \%$} & \multirow{2}{*}{$\begin{array}{c}\text { Bulk } \\
\text { Density, } \\
\mathrm{g} \mathrm{cm}^{-3}\end{array}$} & \multirow{2}{*}{$\begin{array}{c}\text { Saturated } \\
\text { Hydraulic } \\
\text { Conductivity, } \\
\mathrm{cm} \mathrm{d}^{-1}\end{array}$} \\
\hline & $<0.25$ & $0.25-0.425$ & $0.425-0.59$ & $0.59-0.85$ & $0.85-1.4$ & & \\
\hline Fine & 7.0 & 32.7 & 20.5 & 35.8 & 4.1 & 1.56 & 5443.2 \\
\hline Coarse & 0.6 & 3.2 & 6.8 & 23.6 & 65.8 & 1.60 & 11318.4 \\
\hline
\end{tabular}

*Particle diameters are in millimeters. 


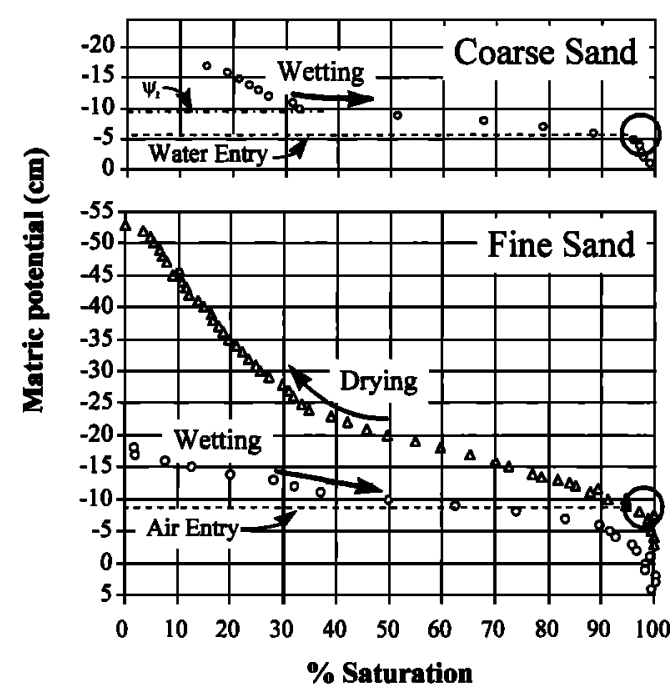

Figure 3. Characteristic curves for the fine soil.

$\left(\phi_{1}\right)$ was changed between experiments by tilting the chamber on a centered fulcrum (Figure 2). The matric potential along the interface was measured with nine tensiometers placed at 19 $\mathrm{cm}$ increments (Figure 2); one tensiometer is located $3 \mathrm{~cm}$ from beyond the end of the toe of the coarse layer. Between experimental runs the chamber was drained until there was no water flowing out of the bottom of the chamber. The drainage period lasted from 24 to 72 hours.

Combinations of four slopes and three rainfall rates provided nine experimental runs (Table 2). Each experimental run was initiated with uniform rainfall until steady state flow was achieved and the flow lines did not change anymore. This typically took about 48 hours for a $120 \mathrm{~mm} \mathrm{~d}^{-1}$ rainfall rate, 24 hours for rainfall rate of $280 \mathrm{~mm} \mathrm{~d}^{-1}$, and about 12 hours for rainfall rate of $680 \mathrm{~mm} \mathrm{~d}^{-1}$.

Once steady state was achieved, the tensiometers were read, and a sequence of three colors (red, yellow, and green) were simultaneously dripped at a slow rate at the surface at $20 \mathrm{~cm}$ intervals; each color was applied twice so a total of $120 \mathrm{~cm}$ of the soil surface received dye (Figure 2). With the aid of the backlighting and the dye traces it was simple to visualize the dyed streamlines and measure the different zones.

\section{Results}

Plate 1 shows photographs of the dyed streamlines from representative experimental runs. The coarse layer appears white in the photographs. Plate 1 shows the coarse layer sloping downhill from right to left, except of course for the three horizontal cases. For all the sloped experimental runs the dye traces were obviously diverted downslope (referred to as capillary diversion) and, in most cases, penetrated the coarse layer at some point (breakthrough). Only for the run sloped at $7.1^{\circ}$ with a flow rate of $120 \mathrm{~mm} \mathrm{~d}^{-1}$, a breakthrough zone did not develop (Plate 1). In most of the experiments a clear lateral flow region without water flowing through the coarse layer formed near the toe of the coarse layer; this will be referred to as the toe diversion in the subsequent discussion.

Table 2 shows the lengths of the three observed flow regimes for all the experiments, namely, the capillary diversion length occurring upslope on the fine-coarse interface, the breakthrough region length, and the toe diversion which occurs downslope on the fine-coarse interface. The length of capillary diversion was measured from the inflection point of the dye trace closest to the upslope end of the chamber to the point where the dye first penetrates into the coarse layer. This length is approximately the same as from the top of the layer to the beginning of the breakthrough region taking into account the "rain shadow" at the uppermost end. The breakthrough region was measured as the total length along the interface through which breakthrough was observed. Toe diversion was measured as the distance between the downslope end of the breakthrough region and the toe of the coarse layer. Because the location of the inflection point, near the fine-coarse interface, of the most uphill dye trace was shifted from experiment to experiment, the total length of the three zones varied. Especially for the $280 \mathrm{~mm} \mathrm{~d}^{-1}$ flow rate for the $11.7^{\circ}$ and $7.1^{\circ}$ slopes, the uphill dye trace was bent to the left and resulted in a shorter length. Also, although the flow domain described in this study is steady state, the boundaries between breakthrough and no breakthrough zones were somewhat difficult to determine with high precision because of diffusion of the dye tracers and the coarse network of dyed streamlines.

A streamline analysis was also performed to better quantify the degree of breakthrough along the interface. The distances between the vertical streamlines in the fine soil $L_{f}$ and between the breakthrough streamlines in the coarse layer $L_{c}$ were mea-

Table 2. The Observed Characteristic Lengths and the Characteristic Parameters of the Funnel and the Breakthrough Flows

\begin{tabular}{|c|c|c|c|c|c|c|}
\hline \multirow[b]{2}{*}{ Run } & \multirow[b]{2}{*}{$\begin{array}{c}\text { Slope, } \\
\text { deg }\end{array}$} & \multirow[b]{2}{*}{$\begin{array}{l}\text { Flow Rate, } \\
\mathrm{mm} \mathrm{d}^{-1}\end{array}$} & \multicolumn{3}{|c|}{ Lengths of the Flow Regimes, cm } & \multirow[b]{2}{*}{ Observed $\psi_{i}, \mathrm{~cm}$} \\
\hline & & & $\begin{array}{c}\text { Toe } \\
\text { Diversion }\end{array}$ & $\begin{array}{c}\text { Breakthrough } \\
\text { Region }\end{array}$ & $\begin{array}{l}\text { Capillary } \\
\text { Diversion }\end{array}$ & \\
\hline 1 & 11.7 & 280 & 16 & 24 & 90 & -9.9 \\
\hline 2 & 11.7 & 680 & 0 & 95 & 43 & -9.2 \\
\hline 3 & 7.1 & 120 & NB & NB & NB & NB \\
\hline 4 & 7.1 & 280 & 18 & 59 & 54 & -9.4 \\
\hline 5 & 7.1 & 680 & 9 & 105 & 29 & -9.6 \\
\hline 6 & 3.5 & 120 & 23 & 70 & 53 & no data \\
\hline 7 & 0 & 120 & 55 & 89 & 0 & NA \\
\hline 8 & 0 & 280 & 25 & 120 & 0 & NA \\
\hline 9 & 0 & 680 & 15 & 130 & 0 & NA \\
\hline
\end{tabular}

NB indicates no breakthrough; NA indicates not applicable. 


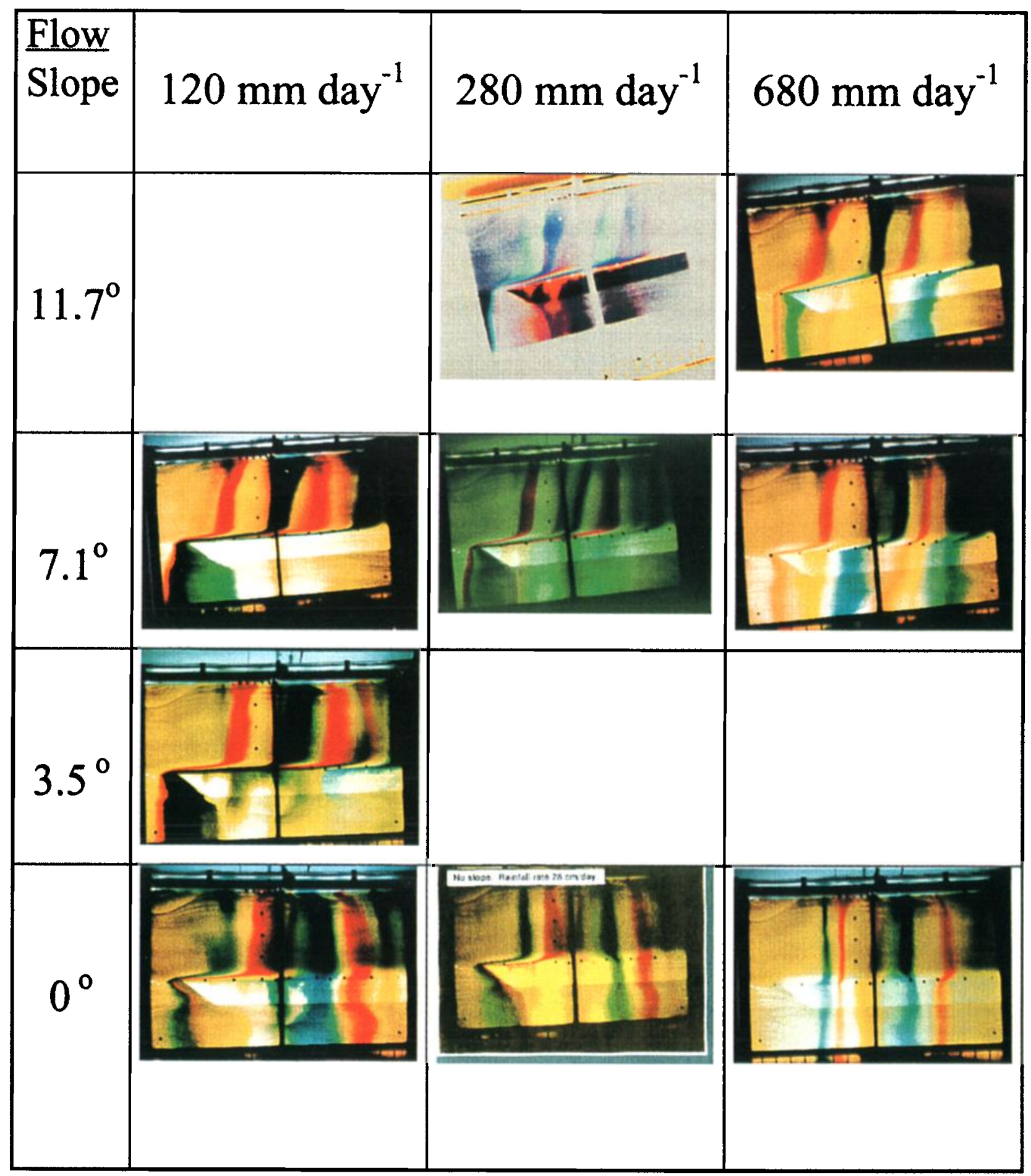

Plate 1. Photographs of experimental runs with dye tracers.

sured, as shown in Figure 4. Using continuity and basic flow net theory, the ratio of the average leakage penetrating into the coarse layer $p$ to the rainfall or infiltration rate $i$ can be implied by the ratio of lengths between vertical streamlines in the fine and coarse layers:

$$
p / i=L_{c} / L_{f},
$$

where $p$ is the average flux penetrating the coarse layer between the dyed streamlines, $L_{f}$ is the distance between stream- lines in the fine layer, and $L_{c}$ is the distance between streamlines penetrating the coarse layer (Figure 4). When $p / i=1.0$, the average leakage, or breakthrough flow, is equal to the rainfall rate; this is referred to as complete breakthrough. Figure 5 shows the $p / i$ ratio along the slope for the three experiments for which enough streamline data could be obtained for this analysis. Each $p / i$ ratio is plotted at the midpoint between the two breakthrough streamlines. As can be seen in Figure 5a, there were insufficient data to calculate $p / i$ for some 


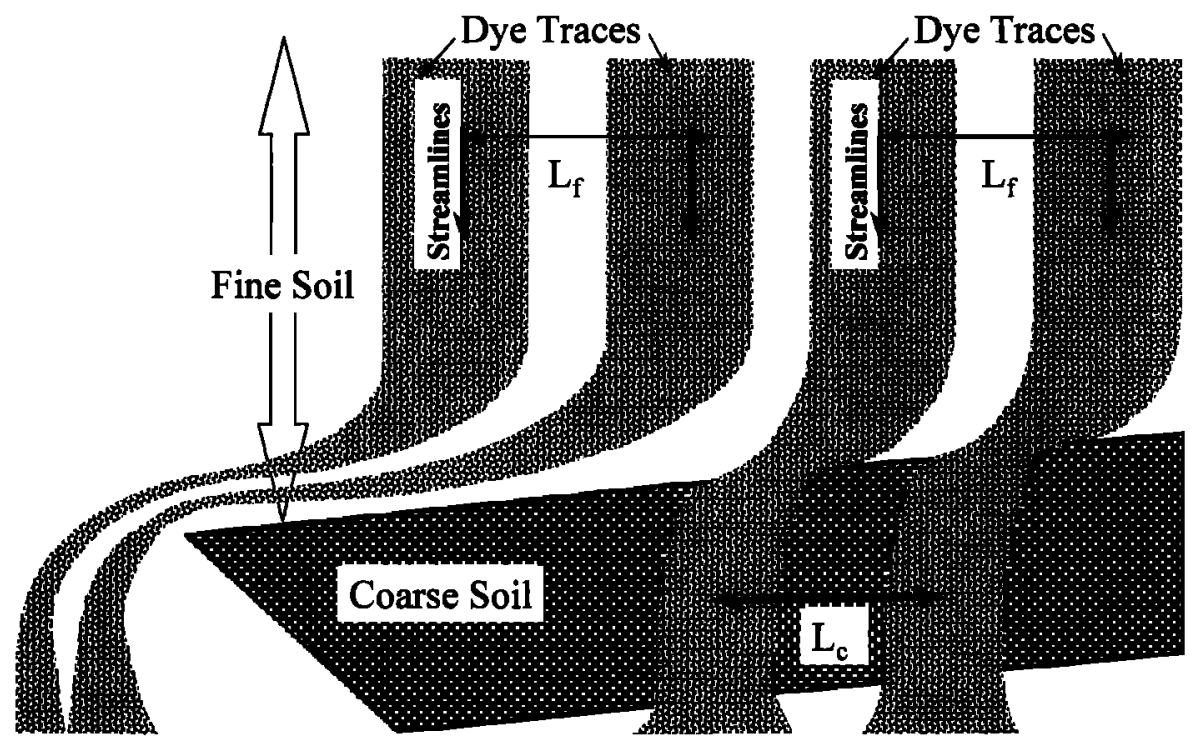

Figure 4. Schematic of dye tracers observed in the experimental chamber and lengths $L$ between various streamlines.

runs; in one run, there was no breakthrough flow, and in others there was only one or part of one streamline in the breakthrough. According to these results, of the three analyzed sloped experiments only the $7.1^{\circ}, 680 \mathrm{~mm} \mathrm{~d}^{-1}$ run reached complete breakthrough; the others apparently attained only partial breakthrough; that is, the magnitude to the breakthrough flow was less than the water application rate. For the $0^{\circ}$ slope the ratio of flow through the layer was approximately 1 (Figure 5b). The average integral of $p / i$ across the break-
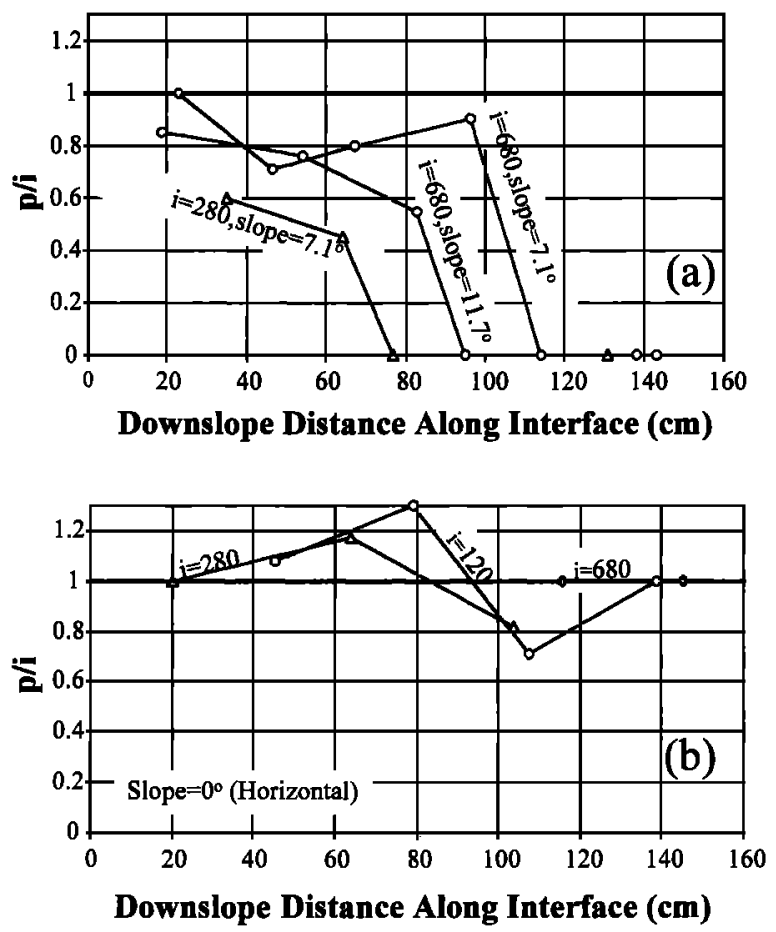

Figure 5. Leakage to infiltration ratios, $p / i$, for six experiments $\left(i\right.$ is in $\left.\mathrm{mm} \mathrm{d}^{-1}\right)$. (a) Sloped coarse layer experiments. (b) Horizontal coarse layer. through regions of the horizontal experiments was 0.99 , which is very close to 1.00 , indicating full breakthrough in the entire breakthrough layer.

The measured matric potential along the fine-coarse interface for the $11.7^{\circ}$ sloped, $7.1^{\circ}$ sloped, and horizontal $\left(0^{\circ}\right)$ experiments as well as the breakthrough regions in each run (patterned areas) are shown in Figure 6. The right-hand sides of the graphs in Figure 6 correspond to the upslope end of the chamber which matches the photographs in Plate 1 . The position of the coarse layer toe is indicated by the vertical, dashed lines in Figure 6. The patterned areas in Figure 6 show the extent of the breakthrough for each infiltration rate; the lightest area corresponds to the $680 \mathrm{~mm} \mathrm{~d}{ }^{-1}$ experiments, the intermediate area corresponds with the $280 \mathrm{~mm} \mathrm{~d}^{-1}$, and the most dense pattern corresponds with the $120 \mathrm{~mm} \mathrm{~d}^{-1}$. In all cases, as expected, the highest curve (least negative matric potential) corresponds to the highest flow rate, and the lowest curve corresponds to the lowest flow rate. Also, as expected, matric potential increases in the downslope direction as diverted water induces moisture accumulation (Figure 6).

In the experiment with the $0^{\circ}$ slope, there are very small differences in the matric potential along the fine-coarse interface in the breakthrough zone (Figure 6), indicating that there is very little sideways flow, and thus full breakthrough is expected. This conclusion is corroborated by the streamline analysis presented before, adding credence to our experimental and streamline analysis methods.

The matric potentials in the breakthrough zone at which full breakthrough occurs (i.e., breakthrough capacity equals the infiltration capacity of the overlying sand) are nearly constant for each flow rate: $\psi_{e}$ equals $-7.7 \mathrm{~cm}$ for $680 \mathrm{~mm} \mathrm{~d}^{-1} ;-8.7 \mathrm{~cm}$ for $280 \mathrm{~mm} \mathrm{~d}^{-1}$; $-9.5 \mathrm{~cm}$ for $120 \mathrm{~mm} \mathrm{~d}^{-1}$. We refer to these potentials as "the effective interface water entry values" because the flow conditions at full breakthrough are similar to those occurring in column studies by Hillel and Gardner [1970].

The matric potential data in the breakthrough region for the sloped experiments suggest the presence of a partial breakthrough. In the sloped experiments, breakthrough occurs at matric potentials less than $\psi_{e}$ (Figure 6); for example, for the 


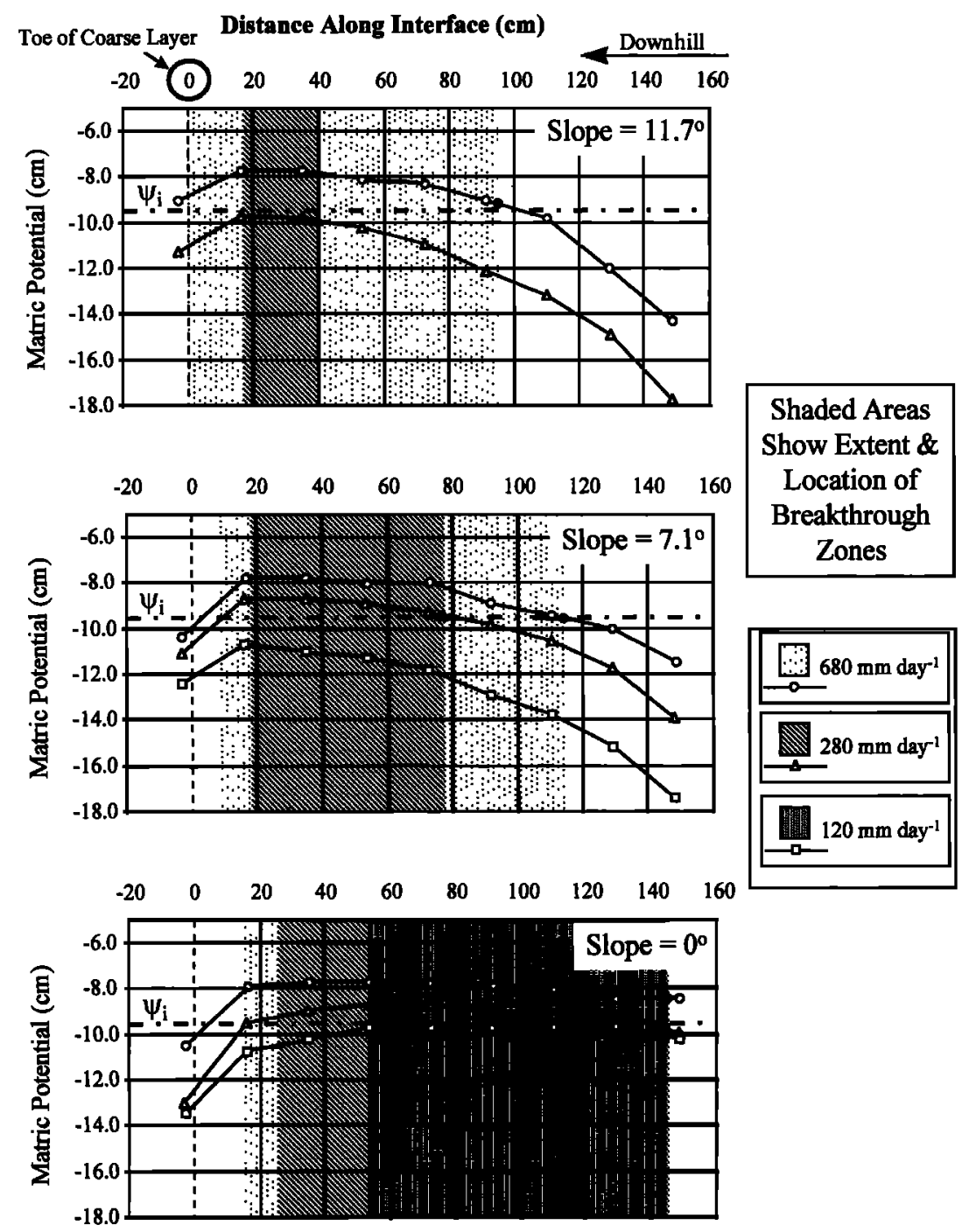

Figure 6. Steady state matric potentials along the fine-coarse interface and location of breakthrough regions for eight experimental runs.

$680 \mathrm{~mm} \mathrm{~d}^{-1}$, horizontal experiment, $\psi_{e}$ is about $-7.7 \mathrm{~cm}$, yet in the sloped experiments with the same water application rate, breakthrough occurs at a lower matric potential, approximately $-9.5 \mathrm{~cm}$. This value varied slightly from experiment to experiment (Table 2) but was generally about $-9.5 \mathrm{~cm}$ (standard deviation of $0.3 \mathrm{~cm}$ ) and is shown by the horizontal dashed lines in Figure 6. This value will be referred to as the initial interface water entry matric potential $\psi_{i}$, at which the narrowest pores at the interface form a continuous network. Under low flow conditions the effective and initial interface water entry matric potential are equal, and the original definition of Hillel and Gardner [1970] is valid for $\psi_{i}$.

Though the matric potential data for the sloped experiments suggest complete breakthrough for several of the runs (Figure 6 ), regions of constant matric potential are only observed among two or three tensiometers. A longer chamber would have allowed better verification if the matric potential contours are parallel within the complete breakthrough regions. The observation of breakthrough at matric potentials lower than $\psi_{e}$ corroborates the existence of a partial breakthrough zone identified in the streamline analysis (Figure 5). Figure 6 shows that the matric potential drops near the downslope edge of the breakthrough region, which suggests that there is a partial breakthrough region on both sides of the complete breakthrough region. Though there were not enough measurements to precisely define the pressure distribution near the toe of the coarse layer, in most experiments a linear interpolation between tensiometers spanning the downslope edge of the breakthrough layer suggests that $\psi_{i}$ may be the point for which breakthrough ceases (Figure 6).

\section{Discussion}

The experiments show three funneled flow regimes: capillary diversion, breakthrough, and toe diversion. Figure 7 is a schematic, based on the results of this study, which summarizes the theoretical partition of flow along an inclined coarse layer of finite length embedded in a fine soil. Table 3 summarizes the important characteristics for each of these funneled flow regimes. Depending upon the conditions, this three-regime description can develop fully or partially. Kung's [1990] original "funnel flow" was actually the case where a breakthrough zone does not develop. Each of the three flow regimes will now be discussed separately, starting at the upslope end. 


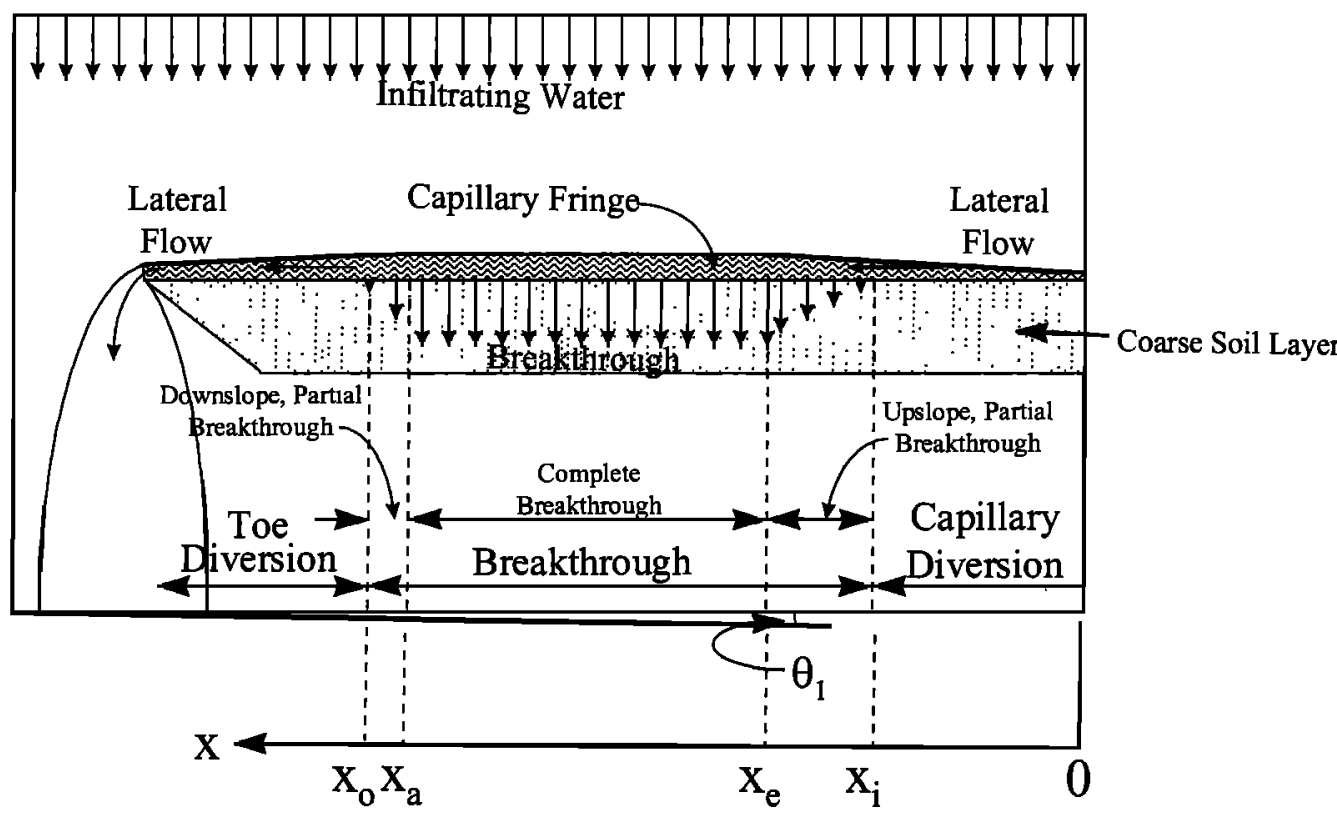

Figure 7. Schematic of the funneled flow system divided laterally into zones of flow along the coarse-fine interface.

\subsection{Capillary Diversion}

The results in Table 2 show that the length of capillary diversion is inversely proportional to the rainfall rate and directly proportional to the inclination of the coarse layer; that is, a high infiltration rate results in a relatively rapid accumulation of water along the fine-coarse interface and therefore a relatively steep increase in matric pressure [Warrick et al., 1997]. A rapid increase in matric pressure translates into a short distance along the interface before the matric potential reaches the initial water entry suction. Steenhuis et al. [1991] extended work by Ross [1990] which mathematically describes the maximum length of the capillary diversion $L_{\mathrm{cd}}$, based on the above principles and an exponential conductivity function:

$$
L_{\mathrm{cd}} \leq \tan \left(\phi_{1}\right)\left[\alpha^{-1}\left(\frac{K_{\mathrm{fs}}}{i}\right)+\frac{K_{\mathrm{fs}}}{i}\left(h_{a}-\psi_{w}^{*}\right)\right],
$$

where $h_{a}$ is the effective air entry value for the fine soil; $\psi_{w}^{*}$ is the water entry value for the soil water characteristic function of the coarse layer, and $\alpha$ is the coefficient in the conductivity function of the form $K=K_{\mathrm{fs}} \exp (-\alpha \psi)$ for $\psi<\psi_{w}^{*}$ and $K=$ $K_{\mathrm{fs}}$ for $\psi \geq \psi_{w}^{*}$. As shown in Figure 3, $h_{a}$ is between -9 and $-10 \mathrm{~cm}$ and $\psi_{w}^{*}=-5 \mathrm{~cm}$. The value for $\alpha$ is $0.58 \mathrm{~cm}^{-1}$. Using these values, (2) predicts capillary diversion lengths which are 3 to 4 times greater than those observed in these experiments. In the derivation of (2) it was assumed that the soil was very dry and that water would enter at the water entry value obtained from the wetting branch of the water characteristic curve of the coarse soil. In our experiment the water entered at an initial interface water entry matric potential $\psi_{i}=-9.5 \mathrm{~cm}$ $( \pm 0.3 \mathrm{~cm})$, which is obviously different than the value derived from the wetting curve of the coarse soil. It is likely that these laboratory experiments represent field conditions more realistically than the "very dry" scenario assumed for (2). Even when the coarse layer is very dry, vapor diffusion will eventually "wet up" the coarse layer when the fine layer is wet as shown. DiCarlo et al. [1999] found for a similar sharp boundary in fingered flow that vapor would move across the boundary wetting up the dry soil. Thus the assumption that the coarse soil stays dry might not be reasonable. Using the initial interface water entry matric potential $\psi_{\iota}=-9.5 \mathrm{~cm}$, instead of $\psi_{w}^{*}$, capillary lengths predicted with (2) fit the observed lengths with $R^{2}=0.98$ and a standard error of $10 \%$ (Figure 8 ). The points lying below the $1: 1$ line are very close to the line and can be reasonably explained by experimental error. The experimental run with a slope of $7.1^{\circ}$ and water application rate of $120 \mathrm{~mm} \mathrm{~d}^{-1}$ (Table 2) did not have breakthrough, meaning that the capillary diversion was greater than $140 \mathrm{~cm}$. Equation (1) underpredicts the capillary diversion $(125 \mathrm{~cm})$, because the toe of the coarse layer began to affect the flow before breakthrough commenced.

Table 3. Characterization of the Funnel Flow Zones Along the Inclined Fine-Coarse Interface

\begin{tabular}{|c|c|c|c|c|}
\hline Location* & Flow Regime & $\begin{array}{c}\text { Matric } \\
\text { Potential } \psi\end{array}$ & $\begin{array}{l}\text { Downslope } \\
\text { Lateral Flow }\end{array}$ & Leakage \\
\hline $\begin{array}{l}0<x<x_{2} \\
x_{2} \leq x<x_{e} \\
x_{e} \leq x<x_{a} \\
x_{a} \leq x<x_{0} \\
x_{0}<x<L\end{array}$ & $\begin{array}{l}\text { capillary diversion } \\
\text { breakthrough region (partial, upslope) } \\
\text { breakthrough region } \\
\text { breakthrough region (partial, downslope) } \\
\text { toe diversion }\end{array}$ & $\begin{array}{l}\psi<\psi_{t} \\
\psi_{1} \leq \psi<\psi_{e} \\
\psi=\psi_{e} \\
\psi_{t} \leq \psi<\psi_{e} \\
\psi<\psi_{t}\end{array}$ & $\begin{array}{l}\text { increasing } \\
\text { decreasing } \\
\text { no flow } \\
\text { increasing } \\
\text { increasing }\end{array}$ & $\begin{array}{l}\text { no breakthrough } \\
\text { increasing downslope } \\
\text { constant, complete breakthrough } \\
\text { decreasing downslope } \\
\text { no breakthrough }\end{array}$ \\
\hline
\end{tabular}

*See Figure 7 for graphical details. 


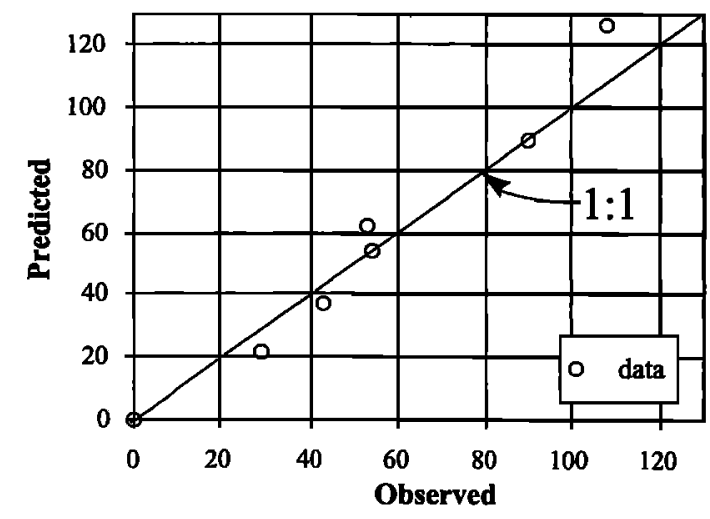

Figure 8. Observed capillary diversion lengths versus predicted maximum lengths using the relationship from Steenhuis et al. [1991].

For the two soils used in this experiment, the air entry value of the fine sand $h_{a}$ is almost equal to the initial interface water entry matric potential. The last term in (1) is then insignificant compared with the first term, and (1) resembles the relationship presented by Ross [1990]. The equation of Ross [1990] then also fits the data very well $\left(R^{2}=0.97\right.$, standard error of $11 \%$ ).

\subsection{Breakthrough}

As mentioned in section 1 , once the pressure increases to initial water entry value $\left(\psi_{l}\right)$, water will move downward into the coarse layer initiating breakthrough. As long as the leakage into the coarse layer is less than the vertical flux from above, water will accumulate along the interface. Once the pressure reaches the effective water entry value $\psi_{e}$, the flow through the coarse layer is equal to the infiltration rate, and there is no "net" downslope lateral flow even though the streamlines continue to be refracted in this region.

The graph of the sloped experiments shown in Figure 5 is instructive when compared to $p / i$ ratios from earlier research. Ross [1990] did not address the values of $p / i$ in the partial breakthrough zone along the interface. He derived the breakthrough length for $p / i=1$. By neglecting the partial breakthrough zone, he thus overpredicted the length of the capillary diversion. Webb [1997] showed numerical simulation results in which the capillary diversion $(p / i=0)$ transition into complete breakthrough was smoothed into an "S" curve. The curves in Figure 5 are distinctly different though exactly why is currently unclear and requires further investigation.

\subsection{Toe Diversion}

The toe diversion is interesting and would not be expected in the "infinite sloping layer" scenario which has received considerable theoretical attention [Oldenburg and Pruess, 1993; Webb, 1997]. The partial breakthrough zone of the toe arises from the rapid decrease in matric potential. The matric potential along the interface becomes so low that water cannot enter into the coarse layer. Though both the capillary diversion and toe diversion are regions of lateral flow only (and no flow through the coarse layer), the mechanisms governing the flow are different. As shown in Table 2, there was relatively minimal correlation between rainfall rate or interface slope. The toe diversion, the region between the toe of the coarse layer and the toe end of the breakthrough region, was generally around $20 \mathrm{~cm}$. The orly exceptions were the extreme cases of (1) no slope and very low rain rate $\left(120 \mathrm{~mm} \mathrm{~d}^{-1}\right)$ in which the toe diversion was enhanced $(55 \mathrm{~cm})$ and (2) steep slope $\left(11.7^{\circ}\right)$ and high rainfall rate $\left(680 \mathrm{~mm} \mathrm{~d}^{-1}\right)$ in which there was no clearly defined toe diversion. The relative similarity of toe diversion length suggests that matric potential gradients immediately below the toe may be more significant to the toe diversion mechanism than slope or water application rate. In Figure 6 the drop in potential near the toe is relatively constant, corroborating the similarity in toe lengths. The relatively long toe diversion in the horizontal, $120 \mathrm{~mm} \mathrm{~d}^{-1}$ run may be better described by studying the temporal development of funneled flow; this type of investigation was outside the focus of this study.

\section{Conclusions}

This study demonstrated funneled flow and breakthrough flow under laboratory conditions. The results agreed well with the theory and provided some new insights into the mechanisms involved. Three zones were experimentally observed and theoretically identified: capillary diversion, breakthrough, and toe diversion.

Of particular interest is the experimental observation of an initial interface water entry matric potential $\psi_{\imath}$, which differs conceptually from other studies. This value appears to influence location of the upslope boundary of the breakthrough region as well as, though not as confidently, the downslope boundary. This is particularly important if previously derived relationships [e.g., Ross, 1990; Steenhuis et al., 1991] are to be used to predict the magnitude of a capillary diversion. Parameterizing such relationships with water entry values obtained from soil characteristic curves may lead to gross overpredictions in the length of capillary diversion. Unlike the effective interface water entry suction $\psi_{e}$, the initial water entry suction $\psi_{i}$ appears to be independent of the flow regime and is likely equal to the matric potential at which the smallest pores in the two media form a continuous path.

Inasmuch as the type strata described in this study occurs in nature, understanding the mechanisms controlling flow around it will be invaluable to practical applications involving pollutant transport, groundwater recharge, and perhaps subsurface storm flow. It may also help in the design of waste disposal facilities.

Acknowledgment. Thanks go to Ole Wendroth and Stephen Webb for their helpful review.

\section{References}

Betson, R. P., J. P. Marius, and R. T. Joyce, Detection of saturated interflow in soils with piezometers, Soil Sci. Soc. Am. Proc., 32, 602-604, 1968.

Beven, K. J., Kinematic subsurface stormflow, Water Resour. Res., 17, 1419-1424, 1981.

Beven, K. J., and P. Germann, Macropores and water flow in soils, Water Resour. Res., 18, 1311-1325, 1982.

Bouma, J., Comment on: Micro-, meso-, and macroporosity of soils, Soil Sci. Soc. Am. J., 45, 1244-1245, 1981.

DiCarlo, D. A., T. W. J. Bauters, C. J. G. Darnault, T. S. Steenhuis, and J.-Y. Parlange, Lateral expansion of preferential flow paths in sands, Water Resour. Res., 35, 427-434, 1999.

Dunne, T., and R. D. Black, An experimental investigation of runoff prediction in permeable soils, Water Resour. Res., 6, 478-490, 1970.

Flury, M., Experimental evidence of transport of pesticides through field soils-A review, J. Environ. Qual., 25, 25-45, 1996. 
Gardner, W. R., Water movement in soil, film, Wash. State Univ., Pullman, 1960

Glass, R. J., J.-Y. Parlange, and T. S. Steenhuis, Mechanisms for finger persistence in homogenous, unsaturated, porous media: Theory and verification, Soil Sci., 148, 60-70, 1989.

Hewlett, J. D., and A. R. Hibbert, Moisture and energy conditions within a sloping soil mass during drainage, J. Geophys. Res., 68, 1081-1087, 1963.

Hill, D. E., and J.-Y. Parlange, Wetting front instability in layered soils, Soil Sci. Soc. Am. J., 36, 697-702, 1972.

Hillel, D., Unstable flow in layered soils: A review, Hydrol. Processes, 1, $143-147,1987$.

Hillel, D., and R. S. Baker, A descriptive theory of fingering during infiltration in layered soils, Soil Sci., 146, 51-56, 1988.

Hillel, D., and W. R. Gardner, Measurements of unsaturated conductivity and diffusivity by infiltration through an impeding layer, Soil Sci., 109, 149-153, 1970.

Hursh, C. R., Storm water and absorption, Eos Trans. AGU, 17, 301302, 1936.

Kirby, M. J., and R. J. Chorley, Throughflow, overland flow and erosion, Bull. Int. Assoc. Sci. Hydrol., 12, 5-21, 1967.

Kung, K.-J. S., Preferential flow in a sandy vadose zone, 2, Mechanisms and implications, Geoderma, 46, 59-71, 1990.

Miyazaki, T., Water flow in unsaturated soil layered slopes, J. Hydrol., 102, 201-214, 1988.

Morris, C. E., and J. C. Stormont, Capillary barriers and subtle D covers: Estimating equivalency, J. Environ. Eng., 123, 3-10, 1997.

Mualem, Y., Anisotropy of unsaturated soils, Soil Sci. Soc. Am. J., 48, 505-509, 1984.

Oldenburg, C. M., and K. Pruess, On numerical modeling of capillary barriers, Water Resour. Res., 29, 1045-1056, 1993.

Pan, L. H., A. W. Warrick, and P. J. Wierenga, Downward water flow through sloping layers in the vadose zone: Time-dependence and effect of slope length, J. Hydrol., 199, 36-52, 1997.

Parlange, J.-Y., and D. E. Hill, Theoretical analysis of wetting front instability in soils, Soil Sci., 122, 236-239, 1976.

Pilgram, D. H., D. D. Huff, and T. D. Steele, A field evaluation of surface subsurface runoff, 2, Runoff processes, J. Hydrol., 38, 319341, 1978.

Ross, B., The diversion capacity of capillary barriers, Water Resour. Res., 26, 2625-2629, 1990.

Selker, J. S., Design of interface shape for protective capillary barriers, Water Resour. Res., 33, 259-260, 1997.

Selker, J. S., J.-Y. Parlange, and T. S. Steenhuis, Wetting front instability in homogenous sandy soils under continuous infiltration, Soil Sci. Soc. Am. J., 56, 1346-1350, 1992.

Stagnitti, F., M. B. Parlange, T. S. Steenhuis, and J.-Y. Parlange,
Drainage from a uniform soil layer on a hillslope, Water Resour. Res., 22, 631-634, 1986.

Steenhuis, T. S., and J.-Y. Parlange, Preferential flow in structured and sandy soils, in Preferential Flow, edited by T. J. Gish and A. Shirmohammadi, pp. 12-21, Am. Soc. Agric. Eng., St. Joseph, Mich., 1991.

Steenhuis, T. S., K.-J. S. Kung, J.-Y. Parlange, J. S. Selker, and X.-X. Chen, Flow regimes in sandy soils with inclined layers, in Proceedings of Tenth Annual Hydrology Days, edited by $\mathrm{H}$. Morel-Seytoux, pp. 78-94, Hydrology Days, Atherton, Calif., 1990.

Steenhuis, T. S., J.-Y. Parlange, and K.-J. S. Kung, Comment on "The diversion capacity of capillary barriers" by Benjamin Ross, Water Resour. Res., 27, 2155-2156, 1991.

Tamai, N., A. Aseda, and C. G. Jeevaraj, Fingering in twodimensional, homogeneous, unsaturated porous media, Soil Sci., 144, 107-112, 1987.

Warrick, A. W., P. J. Wierenga, and L. Pan, Downward water flow through layers in the vadose zone: Analytical solutions for diversions, J. Hydrol., 192, 321-337, 1997.

Webb, S. W., Generalization of Ross' tilted capillary barrier diversion formula for different two-phase characteristic curves, Water Resour. Res., 33, 1855-1859, 1997.

Whipkey, R. Z., Subsurface stormflow from forested watersheds, Bull. Int. Assoc. Sci. Hydrol., 10, 74-85, 1965.

Yeh, T.-C., L. W. Gelhar, and A. L. Gurjahr, Stochastic analysis of unsaturated flow in heterogeneous soils, 2, Observation and applications, Water Resour. Res., 21, 465-471, 1985.

Zaslavsky, D., and G. Sinai, Surface hydrology, 3, Causes of lateral flow, J. Hydraul. Div. Am. Soc. Civ. Eng., 107, 37-52, 1981.

J. Boll, Department of Biological and Agricultural Engineering, University of Idaho, Moscow, ID 83844. (jboll@uidaho.edu)

R. D. Braddock, Environmental Sciences, Griffith University, Nathan, Queensland 4111, Australia. (R.Braddock@ens.gu.edu.au)

A. Heilig, J.-Y. Parlange, and T. S. Steenhuis, Department of Agricultural and Biological Engineering, Cornell University, Ithaca, NY 14853. (ah63@cornell.edu; jp58@cornell.edu; tss1@cornell.edu)

J.-S. Kim, Department of Agricultural Engineering, Chungbuk National University, Chongju 361-763, South Korea. (jskim@cbucc. chungbuk.ac.kr)

J. S. Selker, Department of Bioresource Engineering, Oregon State University, Corvallis, OR 97331. (selkerj@engr.orst.edu)

M. T. Walter, Department of Environmental Science, University of Alaska, Juneau, AK 99801. (mtw5@cornell.edu)

(Received May 14, 1999; revised November 1, 1999; accepted November 2, 1999.) 